\title{
Crescimento e produtividade de nogueira-macadâmia em consórcio com cafeeiro arábica irrigado
}

\author{
Marcos José Perdoná(1), Adriana Novais Martins ${ }^{(2)}$, Eduardo Suguino( ${ }^{(1)}$ e Rogério Peres Soratto ${ }^{(3)}$
}

\begin{abstract}
(1)Agência Paulista de Tecnologia dos Agronegócios (APTA), Regional Centro-Leste, Avenida Bandeirantes, 2.419, CEP 14030-670 Ribeirão Preto, SP. E-mail: marcosperdona@apta.sp.gov.br, esuguino@apta.sp.gov.br (2)APTA, Regional Centro-Oeste, Rua Andrade Neves, 81, CEP 17515-400 Marília, SP. E-mail: adrianamartins@apta.sp.gov.br. (3)Universidade Estadual Paulista, Faculdade de Ciências Agronômicas, Campus de Botucatu, Caixa Postal 237, CEP 18603-970 Botucatu, SP. E-mail: soratto@fca.unesp.br.
\end{abstract}

Resumo - O objetivo deste trabalho foi avaliar o crescimento e a produtividade de cultivares de nogueira-macadâmia (Macadamia integrifolia), em sistema de cultivo consorciado com café (Coffea arabica) irrigado. O experimento foi realizado em delineamento inteiramente ao acaso, com dez repetições. Seis cultivares de macadâmia foram utilizadas, das quais três nacionais (IAC 4-12B, IAC 4-20 e IAC 9-20) e três havaianas (HAES 344, HAES 660 e HAES 816). Nos quatro primeiros anos de produção, foram feitas avaliações de: altura de planta, diâmetro de copa e de tronco, número de nozes por planta, peso médio de noz, peso médio de amêndoa, produção de nozes por planta, taxa de recuperação e produção de amêndoas por planta. As cultivares nacionais apresentaram menor crescimento em altura, com destaque para IAC 4-20, porém, com copas de maior diâmetro. As cultivares nacionais são mais produtivas, com destaque para a IAC 4-12B.

Termos para indexação: Coffea arabica, Macadamia integrifolia, consorciação, noz, porte de planta.

\section{Growth and yield of macadamia nut intercropped with irrigated Arabica coffee}

\begin{abstract}
The objective of this study was to evaluate the growth and yield of macadamia nut (Macadamia integrifolia) cultivars in an intercropped system with irrigated coffee (Coffea arabica). The experiment was carried out in a completely randomized design with ten replicates. Six macadamia cultivars, from which three Brazilian (IAC 4-12B, IAC 4-20, and IAC 9-20) and three Hawaiian (HAES 344, HAES 660, and HAES 816 ) ones were used. In the first four years of production, evaluations were done for: plant height, canopy and stem diameter, number of nuts per plant, nut average weight, almond medium weight, nut production per plant, recovery rate, and almond production per plant. The Brazilian cultivars, especially IAC 4-20, showed a lower height, but with a larger canopy diameter. The Brazilian cultivars are more productive, among which IAC $4-12 B$ is outstanding.
\end{abstract}

Index terms: Coffea arabica, Macadamia integrifolia, intercropping, nut, plant size.

\section{Introdução}

A nogueira-macadâmia (Macadamia integrifolia Maiden \& Betche) é uma planta arbórea, de clima subtropical, de origem australiana. Esta espécie teve maior desenvolvimento tecnológico no Hawaii Agricultural Experiment Station (HAES), onde se deu a criação dos principais clones e cultivares plantados no mundo (McFadyen et al., 2012). A noz-macadâmia tem grande potencial de mercado, mas, ainda, é pouco explorada no Brasil (Schneider et al., 2012), onde as primeiras mudas foram plantadas na década de 1940, no Instituto Agronômico (IAC, Campinas), que iniciou em 1974 o programa de domesticação e melhoramento genético, ao lançar 17 cultivares adaptadas às condições climáticas brasileiras.
O zoneamento agroclimático, realizado para a cultura no Brasil, mostra que extensas áreas são aptas para o plantio, inclusive os estados de São Paulo, Rio de Janeiro, Espírito Santo, sul de Minas Gerais, leste do Mato Grosso do Sul e oeste do Paraná (Schneider et al., 2012).

As plantas de macadâmia apresentam longa vida produtiva; entretanto, segundo Pimentel et al. (2007), o principal gargalo para o desenvolvimento da cultura de macadâmia no Brasil é o longo período necessário para o retorno do capital investido, que é de aproximadamente 11 anos, uma vez que a produção inicia-se aos cinco ou seis anos de idade da planta. Como alternativa para diminuir o período de retorno, sugere-se o plantio consorciado, que reduz os custos de 
implantação e manutenção da cultura e oferece retorno econômico antecipado (Sobierajski et al., 2006).

Desde a década de 1970, a macadâmia é utilizada por produtores de São Paulo e Minas Gerais, em sistemas de consorciação com o cafeeiro. Efeitos benéficos à cultura do café foram verificados por Pezzopane et al. (2010), que registraram redução média de $72 \%$ na incidência de ventos e de $2,2^{\circ} \mathrm{C}$ na temperatura máxima do ar, no cultivo arborizado com macadâmia. Além disso, o consórcio proporciona melhor aproveitamento de mão de obra durante o ano, benefício de grande importância para a agricultura familiar, pois possibilita agregar renda adicional e proporcionar maior sustentabilidade ao sistema de produção (Pezzopane et al., 2007; Vieira et al., 2007). Ricci et al. (2006) relatam que as cultivares de café Tupi, Icatu e Obatã não apresentaram perdas de produtividade nos sistemas sombreados. Nicoleli \& Moller (2006) concluíram que é vantajoso o investimento no cultivo de café sombreado e que a macadâmia é uma das espécies recomendadas para arborização de cafezais (Camargo, 2010). A seleção de plantas de macadâmia, com elevado potencial produtivo e que apresentem baixa concorrência aos cafeeiros, possibilita a implantação do sistema consorciado além de aumentar a rentabilidade dos cafeicultores.

Os benefícios do cultivo em consórcio de café e macadâmia podem ser diversos como: a implantação de um consórcio permanente, com a produção de ambas as culturas se mantendo ao longo dos anos; um consórcio temporário, com vistas à viabilização econômica da implantação de um pomar de macadâmia; ou, ainda, a maximização da produtividade do café, pela atenuação de condições climáticas adversas, por meio de uma simples arborização. Contudo, por ser de cultivo recente no Brasil, as informações disponíveis e as tecnologias recomendadas para a cultura têm sido extrapoladas e adaptadas de pesquisas para as condições edafoclimáticas do Havaí e da Austrália (Marrocos et al., 2003; Sacramento \& Pereira, 2003), e não há informações sobre o comportamento das cultivares de macadâmia nas condições brasileiras, sobretudo nesta modalidade de cultivo.

O objetivo deste trabalho foi avaliar o crescimento e a produtividade de cultivares de nogueira-macadâmia, em sistema de cultivo consorciado com cafeeiro arábica irrigado, para o planejamento dos arranjos das plantas neste sistema.

\section{Material e Métodos}

O experimento foi realizado em propriedade particular, no Município de Dois Córregos, SP $\left(22^{\circ} 21^{\prime} \mathrm{S} ; 48^{\circ} 22^{\prime} \mathrm{W}\right.$, a $753 \mathrm{~m}$ de altitude). Segundo a classificação de Köppen, o clima da região é tropical, com estação seca no inverno, temperatura média anual de $21,2^{\circ} \mathrm{C}$ e regime pluvial anual de $1.342 \mathrm{~mm}$ (Centro de Pesquisas Meteorológicas e Climáticas Aplicadas à Agricultura, 2012).

O solo do local é um Latossolo Vermelho-Amarelo distrófico (Santos et al., 2006). Os resultados da análise química, da camada de $0-20 \mathrm{~cm}$ de profundidade, antes da instalação do experimento, foram: $\mathrm{pH}\left(\mathrm{CaCl}_{2}\right), 5,2$; $\mathrm{P}$ (resina), $5 \mathrm{mg} \mathrm{dm}{ }^{-3} ; \mathrm{MO}, 17 \mathrm{~g} \mathrm{dm}^{-3} ; \mathrm{K}$, 0,8 $\mathrm{mmol}_{\mathrm{c}} \mathrm{dm}^{-3} ; \mathrm{Ca}, 9 \mathrm{mmol}_{\mathrm{c}} \mathrm{dm}^{-3} ; \mathrm{Mg}, 7 \mathrm{mmol}_{\mathrm{c}} \mathrm{dm}^{-3}$; $\mathrm{Al}, 1 \mathrm{mmol}_{\mathrm{c}} \mathrm{dm}^{-3} ; \mathrm{H}+\mathrm{Al}, 18 \mathrm{mmol}_{\mathrm{c}} \mathrm{dm}^{-3}$; saturação por bases, $49 \%$; $\mathrm{S}_{-} \mathrm{SO}_{4}{ }^{2-}, 3 \mathrm{mg} \mathrm{dm}{ }^{-3}$; B (água quente), $0,12 \mathrm{mg} \mathrm{dm}^{-3}$; $\mathrm{Cu}$ (DTPA), 0,4 $\mathrm{mg} \mathrm{dm}^{-3}$; Fe (DTPA), $20 \mathrm{mg} \mathrm{dm}^{-3}$; Mn (DTPA), 3,6 mg dm ${ }^{-3}$; Zn (DTPA), $0,6 \mathrm{mg} \mathrm{dm}^{-3}$. Os resultados da análise granulométrica foram $103 \mathrm{~g} \mathrm{~kg}^{-1}$ de argila, $71 \mathrm{~g} \mathrm{~kg}^{-1}$ de silte e $826 \mathrm{~g} \mathrm{~kg}^{-1}$ de areia.

Utilizou-se o delineamento inteiramente casualizado, com seis tratamentos e dez repetições. Os tratamentos constituíram-se das cultivares de nogueira-macadâmia IAC 9-20, IAC 4-12B, IAC 4-20 (originárias do Instituto Agronômico, Campinas), e da HAES 660, HAES 816 e HAES 344 (originárias do Hawaii Agricultural Experiment Station), todas enxertadas sobre porta-enxertos da cultivar IAC 10-14.

Em fevereiro de 2006, as cultivares de macadâmia foram plantadas em consórcio com a cultivar Obatã, IAC 1669-20 (Coffea arabica L.). Os cafeeiros foram plantados em espaçamento de $3,5 \times 0,7 \mathrm{~m}$, e as plantas de macadâmia no espaçamento de $10,5 \times 4,9 \mathrm{~m}$, em coincidência com as fileiras de café (Figura 1). Assim, entre duas fileiras do consórcio havia duas fileiras de café solteiro. Neste sistema de consórcio, foram plantadas 194 plantas de macadâmia e 3.888 plantas de café por hectare, para se obter um número de plantas viável para cada uma das culturas. Considerandose a importância da polinização cruzada sobre a produtividade, as diferentes cultivares de macadâmia foram plantadas em faixas alternadas, e cada faixa foi composta de quatro fileiras de cada cultivar de macadâmia, em uma área de 4 ha. $\mathrm{Na}$ área total, foram utilizadas 130 plantas de cada cultivar de macadâmia e 15.550 plantas de café. 
As plantas de macadâmia foram adubadas separadamente, segundo recomendações de Barbosa et al. (1996), e os cafeeiros conforme Raij et al. (1996). Foram aplicados, em superfície, $250 \mathrm{~kg} \mathrm{ha}^{-1}$ por ano de N- $\mathrm{P}_{2} \mathrm{O}_{5}-\mathrm{K}_{2} \mathrm{O} 20-05-20$ à macadâmia, e $1.500 \mathrm{~kg} \mathrm{ha}^{-1}$ por ano da mesma formulação ao café. A irrigação por gotejamento foi instalada em fevereiro de 2006, anteriormente ao plantio das mudas, e composto por gotejadores autocompensantes, espaçados $0,7 \mathrm{~m}$ entre si, e vazão de 1,0 L por hora em cada gotejador. O manejo da irrigação foi realizado com sensores de tensão de água de $25 \mathrm{kPa}$ (sistema Irrigas), instalados nas profundidades de 20 e $60 \mathrm{~cm}$, para manter sempre úmido o sensor instalado a $20 \mathrm{~cm}$.

As avaliações de crescimento foram realizadas sempre no mês de fevereiro, a partir do terceiro ano após o plantio. A altura das plantas - da superfície do solo até o ápice - foi medida com uma régua graduada, colocada rente ao tronco das plantas. O diâmetro da copa foi medido com uma régua na posição horizontal, paralela à orientação da fileira de cafeeiros. $\mathrm{O}$ diâmetro do caule foi avaliado a $5 \mathrm{~cm}$ de altura do solo, com o auxílio de um paquímetro.

As colheitas foram realizadas mediante três coletas dos frutos caídos ao solo, entre fevereiro e abril de cada ano, a partir do terceiro ano após o plantio. Em seguida à colheita, os frutos foram secos à sombra até atingir valores entre 10 e $11 \%$ de umidade, e foram determinadas as seguintes variáveis: número de nozes por planta; peso médio de uma noz (tendo-se pesado uma amostra de 100 nozes por planta); produção de nozes (casca com amêndoa, sem carpelo) por planta; peso médio de uma amêndoa (mediante a quebra, limpeza e pesagem das amêndoas de uma amostra de 100 nozes por planta); taxa de recuperação (TR) (pela

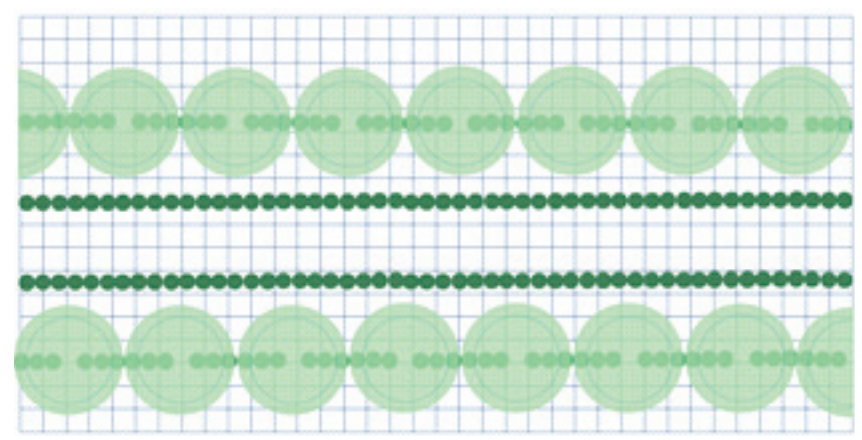

Figura 1. Croquis em escala do diâmetro de copa da cultivar de macadâmia IAC 4-12B. Em verde-claro, 2012; em linha pontilhada, 2009; em verde-escuro, cafeeiros. determinação da percentagem de amêndoa em relação ao peso total da noz); e produção de amêndoas por planta, mediante a multiplicação da produção de nozes pela taxa de retorno, dividida por 100 (Sobierajski et al., 2006).

Os dados foram analisados com o auxílio do programa estatístico SAS, e as médias comparadas pelo teste de Tukey, a 5\% de probabilidade.

\section{Resultados e Discussão}

Desde a primeira avaliação, realizada três anos após o plantio, a cultivar HAES 660 esteve entre as de maior altura de plantas e, ao final, se destacou como a de maior altura, porém, sem diferir significativamente da HAES 344 (Tabela 1). A cultivar HAES 344, que esteve entre as mais baixas no início, igualou-se à mais alta a partir de 2011. A cultivar HAES 816 apresentou valores intermediários, ao início e final das avaliações, e foi a de menor altura entre as cultivares de origem havaiana.

Tabela 1. Altura de planta, diâmetro de copa e diâmetro de tronco de seis cultivares de nogueira-macadâmia, em consórcio com cafeeiro arábica irrigado em Dois Córregos, $\mathrm{SP}^{(1)}$.

\begin{tabular}{|c|c|c|c|c|}
\hline \multirow[t]{2}{*}{ Cultivar } & \multicolumn{4}{|c|}{ Ano } \\
\hline & 2009 & 2010 & 2011 & 2012 \\
\hline & \multicolumn{4}{|c|}{ Altura de planta (m) } \\
\hline IAC 4-12B & $4,1 \mathrm{a}$ & $4,8 \mathrm{a}$ & $4,9 \mathrm{bc}$ & $5,0 \mathrm{c}$ \\
\hline IAC 4-20 & $3,5 \mathrm{c}$ & $3,8 \mathrm{~d}$ & $4,1 \mathrm{~d}$ & $4,4 d$ \\
\hline IAC 9-20 & $3,9 \mathrm{ab}$ & $4,3 \mathrm{bc}$ & $4,7 \mathrm{c}$ & $5,3 b$ \\
\hline HAES 344 & $3,5 \mathrm{c}$ & $4,1 \mathrm{~cd}$ & $5,1 \mathrm{ab}$ & $5,6 \mathrm{ab}$ \\
\hline HAES 660 & $4,1 \mathrm{a}$ & $4,7 \mathrm{ab}$ & $5,3 \mathrm{a}$ & $5,8 \mathrm{a}$ \\
\hline HAES 816 & $3,7 \mathrm{bc}$ & $4,9 \mathrm{a}$ & $5,1 \mathrm{ab}$ & $5,4 \mathrm{~b}$ \\
\hline \multirow[t]{2}{*}{$\mathrm{CV}(\%)$} & 6,4 & 7,4 & 4,7 & 4,1 \\
\hline & \multicolumn{4}{|c|}{ Diâmetro de copa (m) } \\
\hline IAC $4-12 B$ & $3,8 \mathrm{a}$ & $4,4 \mathrm{a}$ & $4,8 \mathrm{a}$ & $4,9 \mathrm{a}$ \\
\hline IAC 4-20 & $2,7 \mathrm{c}$ & $3,5 \mathrm{c}$ & $4,1 \mathrm{c}$ & $4,4 b$ \\
\hline IAC 9-20 & $3,2 b$ & $3,9 b$ & $4,4 b$ & $4,9 \mathrm{a}$ \\
\hline HAES 344 & $2,2 \mathrm{~d}$ & $2,8 \mathrm{e}$ & $3,2 \mathrm{e}$ & $3,9 \mathrm{c}$ \\
\hline HAES 660 & $2,3 \mathrm{~cd}$ & $3,0 \mathrm{de}$ & $3,5 \mathrm{~d}$ & $3,8 \mathrm{c}$ \\
\hline HAES 816 & $2,2 \mathrm{~d}$ & $3,2 \mathrm{~cd}$ & $3,9 \mathrm{c}$ & $4,0 \mathrm{c}$ \\
\hline \multirow[t]{2}{*}{$\mathrm{CV}(\%)$} & 11,0 & 8,1 & 4,2 & 3,4 \\
\hline & \multicolumn{4}{|c|}{ Diâmetro de tronco $(\mathrm{mm})$} \\
\hline IAC 4-12B & $101,9 \mathrm{a}$ & $116,6 \mathrm{a}$ & $140,8 \mathrm{a}$ & $162,1 \mathrm{a}$ \\
\hline IAC 4-20 & $83,4 \mathrm{bc}$ & $101,8 \mathrm{c}$ & $124,9 \mathrm{~b}$ & $137,0 \mathrm{c}$ \\
\hline IAC 9-20 & $92,1 \mathrm{~b}$ & $114,6 \mathrm{ab}$ & $122,9 \mathrm{~b}$ & $153,6 \mathrm{ab}$ \\
\hline HAES 344 & $78,5 \mathrm{c}$ & $101,3 \mathrm{c}$ & $121,8 b$ & $138,3 \mathrm{c}$ \\
\hline HAES 660 & $80,8 \mathrm{c}$ & $106,2 \mathrm{bc}$ & $124,8 b$ & $136,0 \mathrm{c}$ \\
\hline HAES 816 & $79,6 \mathrm{c}$ & $105,4 \mathrm{bc}$ & $122,3 b$ & $142,7 \mathrm{bc}$ \\
\hline $\mathrm{CV}(\%)$ & 8,4 & 7,0 & 6,8 & 6,5 \\
\hline
\end{tabular}

Pesq. agropec. bras., Brasília, v.47, n.11, p.1613-1620, nov. 2012 
As cultivares IAC 4-12B e IAC 9-20 igualaram-se à mais alta até o primeiro ano de avaliação, porém, em 2012, apresentaram alturas intermediárias. A IAC 4-20, a partir das avaliações de 2010, se destacou como a de menor porte.

$\mathrm{Na}$ consorciação de cultivos, a radiação solar incidente nos cafeeiros é um dos principais elementos meteorológicos que podem ser modificados (Pezzopane et al., 2005), está relacionada à arquitetura da planta utilizada no sombreamento (Pezzopane et al., 2010) e será tanto menor quanto maior for a altura da planta sombreadora. De acordo com DaMatta (2004) e Jaramillo-Botero et al. (2010), o sombreamento excessivo prejudica a produtividade do cafeeiro e, de modo geral, o crescimento vertical das plantas de macadâmia foi mais acentuado nas cultivares havaianas (média final de 5,6 m) que nas nacionais (média de 4,9 m) (Tabela 1). Pezzopane et al. (2011) verificaram que a transmissividade da radiação fotossinteticamente ativa (RFA) a $5 \mathrm{~m}$ de altura, em cafeeiro plantado em consórcio com cultivares de macadâmia (120 plantas por ha), apresentou valores inferiores aos $80 \%$ das de lavouras a pleno sol; estes autores inferiram que, nessa condição, os cafeeiros situados nas linhas contíguas às de macadâmia poderiam apresentar diminuição da produtividade de grãos. Para DaMatta (2004), o sombreamento acima de $20 \%$ pode diminuir a produção dos cafeeiros. Portanto, as plantas de macadâmia de menor porte, como a IAC 4-20, são mais recomendadas ao consórcio.

A cultivar IAC 4-12B apresentou os maiores valores de diâmetro de copa em todas as avaliações; porém, não diferiu da IAC 9-20, em 2012 (Tabela 1). A cultivar IAC 4-20 sempre apresentou valores inferiores aos das demais cultivares nacionais e superiores aos das havaianas quanto ao diâmetro de copa. Em geral, as cultivares havaianas apresentaram menores diâmetros de copa, em todas as avaliações. Observou-se que as cultivares originárias do IAC apresentaram copas com formato arredondado, ou seja, com menor altura e maior diâmetro, e as havaianas com formato cônico, eram mais estreitas, porém mais altas. As cultivares nacionais apresentaram um maior ângulo de inserção dos ramos laterais na haste principal, com maior crescimento horizontal $(4,7 \mathrm{~m}$ em média), em comparação às havaianas $(3,9 \mathrm{~m})$.

Em 2011, cinco anos após o plantio, os ramos das plantas da cultivar IAC 4-12B, espaçadas em 4,9 m entre si, já estavam na iminência de se encontrar no sentido da fileira e, no ano seguinte (2012), a cultivar IAC 9-20 também fechou os espaços na fileira, formando um renque. A cultivar IAC 4-20, que se destacou pela menor altura, também apresentou o menor diâmetro de copa entre as cultivares nacionais (Tabela 1). Contudo, em todas as cultivares provenientes do IAC, o vigoroso crescimento horizontal, além de concorrer por espaço e luz com os cafeeiros, também provocou "fechamento" das entrelinhas e impediu a mecanização do sistema. Para mantê-la, podas seriam necessárias logo após a primeira safra (2009) e, certamente, as plantas iriam sofrer diminuição de produtividade nas safras seguintes, uma vez que na nogueira-macadâmia, a maioria das inflorescências ocorre em ramos com mais de um ano, e este tipo de manejo eliminaria boa parte deles (Sacramento \& Pereira, 2003; McFadyen, 2011).

A presença de renques de macadâmia modifica o microclima no interior da lavoura e diminui a incidência de radiação fotossinteticamente ativa sobre as plantas de café (Pezzopane et al., 2010). A descontinuidade de cobertura em sistemas arborizados causa diferenças nas transmissões em diferentes pontos do sistema, e o tipo de copa da árvore utilizada e sua densidade de sombreamento influenciam diferentemente a incidência da radiação, nos diversos pontos do consórcio, que pode variar entre 17 e $87 \%$ da RFA a pleno sol (Pezzopane et al., 2011). Portanto, plantas com menor desenvolvimento horizontal permitem maior transmissividade à radiação solar dentro do sistema. As cultivares HAES 660, HAES 816, e HAES 344 tiveram menor crescimento lateral (Tabela 1), se projetaram menos sobre as plantas de café da mesma linha e, portanto competiram menos por espaço e luz.

O diâmetro do tronco fornece indicativos sobre desempenho em porte e vigor de cada cultivar para a região. A cultivar com maior diâmetro de tronco foi a IAC 4-12B, porém não diferiu da IAC 9-20 nas avaliações realizadas em 2010 e 2012 (Tabela 1). As cultivares HAES 816, HAES 344 e HAES 660 apresentaram diâmetros de tronco menores, especialmente em comparação à cultivar IAC 4-12B. Contudo, houve pequena variação entre as cultivares estudadas.

Apesar de apresentar menor porte, a cultivar IAC 4-20 esteve entre as que produziram maior número de frutos por planta, tendo produzido, na soma de todos os anos, número de frutos significativamente superior 
aos das demais cultivares (Tabela 2). Em geral, as cultivares IAC 4-12B e IAC 9-20 obtiveram valores intermediários para número de nozes por planta, mas superiores aos das cultivares de origem havaiana. Entre as havaianas, a cultivar HAES 816 apresentou o maior número de nozes, porém, sem diferir da HAES 344 na soma dos quatro anos de produção. Na média, as cultivares brasileiras produziram mais que o dobro de frutos por planta do que as de origem havaiana.

O peso médio de noz variou consideravelmente entre as cultivares e entre os anos (Tabela 2). Contudo, as cultivares IAC 4-12B, HAES 816 e HAES 344 apresentaram as maiores médias e a IAC 4-20 a menor. Assim, o maior número de frutos produzidos pela IAC 4-20 não foi suficiente para torná-la a cultivar com maior produção de nozes por planta (Tabela 2). Valores de peso médio de noz semelhantes também foram obtidos por Penoni et al. (2011), com: 7,45 g

Tabela 2. Número de nozes por planta, peso médio de noz e produção de nozes por planta de seis cultivares de macadâmia, em consórcio com cafeeiro irrigado em Dois Córregos, $\mathrm{SP}^{(1)}$.

\begin{tabular}{|c|c|c|c|c|c|}
\hline \multirow[t]{2}{*}{ Cultivar } & \multicolumn{4}{|c|}{ Ano } & \multirow{2}{*}{$\begin{array}{l}\text { Total/ } \\
\text { Média }\end{array}$} \\
\hline & 2009 & 2010 & 2011 & 2012 & \\
\hline & \multicolumn{5}{|c|}{ Número de nozes por planta } \\
\hline IAC $4-12 B$ & $132,8 \mathrm{a}$ & $771,0 \mathrm{~b}$ & $2.421,5 \mathrm{a}$ & $2.555,5 \mathrm{ab}$ & $5.880,7 \mathrm{~b}$ \\
\hline IAC $4-20$ & $106,2 \mathrm{a}$ & $959,0 \mathrm{a}$ & $2.705,8 \mathrm{a}$ & $2.888,7 \mathrm{a}$ & $6.659,7 \mathrm{a}$ \\
\hline IAC 9-20 & $121,7 \mathrm{a}$ & $650,1 b$ & $2.564,5 \mathrm{a}$ & $2.250,3 b$ & $5.586,6 \mathrm{~b}$ \\
\hline HAES 344 & $66,9 b$ & $303,3 \mathrm{c}$ & $1.418,8 \mathrm{~b}$ & $1.173,6 \mathrm{~cd}$ & $2.962,6 \mathrm{~cd}$ \\
\hline HAES 660 & $52,2 \mathrm{bc}$ & $293,2 c$ & $1.299,6 \mathrm{~b}$ & $837,3 \mathrm{~d}$ & $2.482,2 d$ \\
\hline HAES 816 & $39,0 \mathrm{c}$ & $259,9 \mathrm{c}$ & $1.655,3 \mathrm{~b}$ & $1.342,5 \mathrm{c}$ & $3.296,7 \mathrm{c}$ \\
\hline \multirow[t]{2}{*}{ CV (\%) } & 23,6 & 25,0 & 18,0 & 15,6 & 11,5 \\
\hline & \multicolumn{5}{|c|}{ Peso médio de noz (g) } \\
\hline IAC $4-12 B$ & $6,8 b$ & $6,9 \mathrm{bc}$ & $8,3 \mathrm{a}$ & $7,4 \mathrm{bc}$ & $7,7 \mathrm{a}$ \\
\hline IAC 4-20 & $4,7 \mathrm{e}$ & $4,9 \mathrm{e}$ & $5,5 \mathrm{c}$ & $4,9 \mathrm{e}$ & $5,1 \mathrm{~d}$ \\
\hline IAC 9-20 & $5,5 \mathrm{~d}$ & $6,7 \mathrm{~cd}$ & $6,9 b$ & $7,1 \mathrm{~cd}$ & $6,9 b$ \\
\hline HAES 344 & $8,4 \mathrm{a}$ & $7,8 \mathrm{a}$ & $7,6 \mathrm{ab}$ & $7,6 \mathrm{ab}$ & $7,6 \mathrm{a}$ \\
\hline HAES 660 & $6,0 \mathrm{~cd}$ & $6,3 \mathrm{~d}$ & $6,0 \mathrm{c}$ & $7,0 \mathrm{~d}$ & $6,4 \mathrm{c}$ \\
\hline HAES 816 & $6,4 \mathrm{bc}$ & $7,5 \mathrm{ab}$ & $7,6 \mathrm{ab}$ & $7,9 \mathrm{a}$ & $7,7 \mathrm{a}$ \\
\hline \multirow[t]{2}{*}{$\mathrm{CV}(\%)$} & 6,6 & 7,0 & 8,7 & 3,8 & 4,3 \\
\hline & \multicolumn{5}{|c|}{ Produção de nozes (g por planta) } \\
\hline IAC $4-12 B$ & $897,7 \mathrm{a}$ & $5.337,4 \mathrm{a}$ & $19.943,5 \mathrm{a}$ & $18.854,4 \mathrm{a}$ & $45.033,0 \mathrm{a}$ \\
\hline IAC $4-20$ & $500,5 b$ & $4.531,8 b$ & $14.894,6 \mathrm{bc}$ & $14.156,9 \mathrm{~b}$ & $34.083,8 \mathrm{c}$ \\
\hline IAC 9-20 & $673,8 b$ & $4.317,4 \mathrm{~b}$ & $17.488,0 \mathrm{ab}$ & $15.895,0 \mathrm{~b}$ & $38.374,1 \mathrm{~b}$ \\
\hline HAES 344 & $559,7 \mathrm{~b}$ & $2.364,6 \mathrm{c}$ & $10.680,9 \mathrm{~d}$ & $8.943,6 \mathrm{c}$ & $22.548,9 \mathrm{~d}$ \\
\hline HAES 660 & $313,4 \mathrm{c}$ & $1.836,7 \mathrm{c}$ & $7.728,6 \mathrm{e}$ & $5.878,0 \mathrm{~d}$ & $15.756,7 \mathrm{e}$ \\
\hline HAES 816 & $250,4 \mathrm{c}$ & $1.919,8 \mathrm{c}$ & $12.516,1 \mathrm{~cd}$ & $10.630,9 \mathrm{c}$ & $25.317,1 \mathrm{~d}$ \\
\hline $\mathrm{CV}(\%)$ & 26,2 & 17,5 & 15,8 & 16,1 & 10,7 \\
\hline
\end{tabular}

${ }^{(1)}$ Médias seguidas de letras iguais, nas colunas, não diferem pelo teste de Tukey a $5 \%$ de probabilidade. para a IAC 9-20, 7,42g para a IAC 4-12B e 8,06 g para a HAES 816 , porém, esses autores pesaram as nozes logo após a colheita e não definiram a umidade delas.

Ao longo dos quatro primeiros anos de produção, a cultivar IAC 4-12B produziu mais de $45 \mathrm{~kg}$ de nozes por planta e foi superior às demais (Tabela 2). A cultivar HAES 660, que apresentou menor número de nozes por planta e um dos menores pesos médios de noz, foi a cultivar que produziu a menor quantidade de nozes (15,8 $\mathrm{kg}$ por planta). As cultivares brasileiras apresentaram o melhor desempenho em produção de nozes do que as havaianas.

$\mathrm{Na}$ média dos anos, os menores valores de TR foram obtidos pela cultivar IAC 9-20 e os maiores pela HAES 816, e as demais apresentaram valores intermediários (Tabela 3). As cultivares HAES 816 e IAC 4-20 tiveram valores acima das médias alcançadas na Austrália (33\%), e as cultivares IAC 4-12B, HAES 660, HAES 344 e IAC 9-20 apresentaram

Tabela 3. Taxa de recuperação, peso médio de amêndoa e produção de amêndoas por planta de seis cultivares de macadâmia, em consórcio com cafeeiro irrigado em Dois Córregos, $\mathrm{SP}^{(1)}$.

\begin{tabular}{|c|c|c|c|c|c|}
\hline \multirow[t]{2}{*}{ Cultivar } & \multicolumn{4}{|c|}{ Ano } & \multirow{2}{*}{$\begin{array}{l}\text { Total/ } \\
\text { Média }\end{array}$} \\
\hline & 2009 & 2010 & 2011 & 2012 & \\
\hline & \multicolumn{5}{|c|}{ Taxa de recuperação (\%) } \\
\hline IAC 4-12B & $31,1 \mathrm{bcd}$ & $27,9 b$ & $31,2 \mathrm{~b}$ & $33,6 b c$ & $31,8 \mathrm{c}$ \\
\hline IAC $4-20$ & $33,1 \mathrm{ab}$ & $33,3 \mathrm{a}$ & $31,9 b$ & $35,0 \mathrm{~b}$ & $33,3 b$ \\
\hline IAC 9-20 & $29,8 \mathrm{~d}$ & $27,7 \mathrm{~b}$ & $28,5 \mathrm{c}$ & $26,0 \mathrm{e}$ & $27,4 \mathrm{e}$ \\
\hline HAES 344 & $30,6 \mathrm{~cd}$ & $29,1 \mathrm{~b}$ & $30,3 \mathrm{bc}$ & $28,5 \mathrm{~d}$ & $29,5 \mathrm{~d}$ \\
\hline HAES 660 & $33,6 a$ & $33,1 \mathrm{a}$ & $32,3 b$ & $33,4 \mathrm{c}$ & $32,9 \mathrm{bc}$ \\
\hline HAES 816 & $32,3 \mathrm{ab}$ & $34,7 \mathrm{a}$ & $38,5 \mathrm{a}$ & $37,8 \mathrm{a}$ & $37,9 \mathrm{a}$ \\
\hline \multirow[t]{2}{*}{$\mathrm{CV}(\%)$} & 5,0 & 6,24 & 6,1 & 3,5 & 3,1 \\
\hline & \multicolumn{5}{|c|}{ Peso médio de amêndoa $(\mathrm{g})$} \\
\hline IAC 4-12B & $2,1 b$ & $1,9 \mathrm{~cd}$ & $2,6 b$ & $2,5 b$ & $2,4 b$ \\
\hline IAC 4-20 & $1,6 \mathrm{c}$ & $1,6 \mathrm{e}$ & $1,8 \mathrm{~d}$ & $1,7 \mathrm{e}$ & $1,7 \mathrm{f}$ \\
\hline IAC 9-20 & $1,6 \mathrm{c}$ & $1,8 \mathrm{de}$ & $1,9 \mathrm{~d}$ & $1,8 \mathrm{e}$ & $1,9 \mathrm{e}$ \\
\hline HAES 344 & $2,6 a$ & $2,3 b$ & $2,3 \mathrm{c}$ & $2,2 \mathrm{~d}$ & $2,3 \mathrm{c}$ \\
\hline HAES 660 & $2,0 \mathrm{~b}$ & $2,1 \mathrm{bc}$ & $1,9 \mathrm{~d}$ & $2,4 \mathrm{c}$ & $2,1 \mathrm{~d}$ \\
\hline HAES 816 & $2,1 \mathrm{~b}$ & $2,6 \mathrm{a}$ & $2,9 \mathrm{a}$ & $3,0 \mathrm{a}$ & $2,9 \mathrm{a}$ \\
\hline \multirow[t]{2}{*}{$\mathrm{CV}(\%)$} & 7,7 & 8,8 & 8,5 & 4,4 & 4,6 \\
\hline & \multicolumn{5}{|c|}{ Produção de amêndoas (g por planta) } \\
\hline IAC $4-12 B$ & $279,6 \mathrm{a}$ & $1.488,1 \mathrm{a}$ & $6252,8 \mathrm{a}$ & $6.337,4 \mathrm{a}$ & $14.357,8 \mathrm{a}$ \\
\hline IAC 4-20 & $165,9 \mathrm{~b}$ & $1.517,5 \mathrm{a}$ & $4740,3 \mathrm{~b}$ & $4.942,9 b$ & $11.366,6 \mathrm{~b}$ \\
\hline IAC 9-20 & $200,9 b$ & $1.195,7 \mathrm{~b}$ & $4977,7 b$ & $4.146,4 b$ & $10.520,7 \mathrm{bc}$ \\
\hline HAES 344 & $170,9 \mathrm{~b}$ & $690,8 \mathrm{c}$ & $3236,9 \mathrm{c}$ & $2.557,0 \mathrm{c}$ & $6.655,7 \mathrm{~d}$ \\
\hline HAES 660 & $105,2 \mathrm{c}$ & $613,3 c$ & $2499,7 \mathrm{c}$ & $1.968,4 \mathrm{c}$ & $5.186,5 \mathrm{~d}$ \\
\hline HAES 816 & $81,1 \mathrm{c}$ & $665,4 \mathrm{c}$ & $4841,1 \mathrm{~b}$ & $4.017,3 \mathrm{~b}$ & $9.604,9 \mathrm{c}$ \\
\hline $\mathrm{CV}(\%)$ & 26,8 & 19,9 & 17,9 & 17,7 & 12,0 \\
\hline
\end{tabular}

Pesq. agropec. bras., Brasília, v.47, n.11, p.1613-1620, nov. 2012 
médias acima das médias atingidas na África do Sul (25\%) e EUA (24\%), apontadas por Sobierajski et al. (2006). O plantio intercalar das cultivares aumenta a polinização cruzada e melhora a TR (Sobierajski et al., 2007). Penoni et al. (2011) obtiveram valores proporcionais, porém pouco superiores ao do presente trabalho: $32,54 \%$ para IAC $9-20,37,42 \%$ para IAC $4-12 B$ e $39,70 \%$ para HAES 816 , provavelmente por ter efetuado suas medições logo após a colheita, sem ter secado as nozes.

Um dos principais intentos do consórcio é proporcionar rendimento financeiro superior ao do cultivo solteiro, para a área em questão, e é sabido que as indústrias pagam ágios por lotes com maiores taxas de recuperação, pois isso melhora o rendimento do processamento. Portanto, a quantidade de nozes produzidas é importante, mas a qualidade do produto representada pela TR é fator decisivo na formação do preço e na lucratividade do investimento (Pimentel et al., 2007).

Em 2009, a cultivar HAES 344 apresentou o maior peso médio de amêndoa, enquanto as cultivares IAC 4-20 e IAC 9-20 apresentaram os menores valores (Tabela 3). A IAC 4-20, que produziu nozes com menor peso médio, também produziu as amêndoas de menor peso a partir de 2010 e na média dos anos. A cultivar HAES 816 produziu amêndoas com maior peso na média dos anos. Os resultados encontrados foram inferiores aos observados por Penoni et al. (2011), que foram de 2,42 g para a IAC 9-20, 2,77 g para a IAC 4-12B e 3,20 g para a HAES 816 , e seguindo as mesmas tendências, justificados pela não secagem do material. A cultivar IAC 4-12B apresentou a maior produção de amêndoas por planta, com valor médio quase três vezes maior que o obtido pela cultivar HAES 660, que apresentou a menor produção (Tabela 3).

Constatou-se que quando conduzidas sob o sistema de cultivo consorciado com cafeeiro irrigado, as seis cultivares de macadâmia estudadas apresentaram boa produção, desde o terceiro ano de idade, e acumularam produções entre 15 e $45 \mathrm{~kg}$ de nozes por planta no período (Tabela 2). A literatura destaca que a produção de nozes em plantas de macadâmia, no cultivo solteiro, inicia-se entre cinco e seis anos após o plantio no campo (Martin, 1992). Pimentel et al. (2007) obtiveram, em cultivo solteiro, produção acumulada de $1.560 \mathrm{~kg} \mathrm{ha}^{-1}$ de nozes, em plantas de macadâmia de seis anos de idade. No presente experimento, em sistema de cultivo consorciado com café irrigado, mesmo as cultivares havaianas que foram menos produtivas já haviam produzido em média $4.114 \mathrm{~kg} \mathrm{ha}^{-1}$, e as nacionais $7.598 \mathrm{~kg} \mathrm{ha}^{-1}$, com início da produção no terceiro ano após o plantio no campo, ou seja, reduziu-se o período juvenil das plantas. Estes resultados são importantes para a redução do alto período de retorno do investimento, apontado por Pimentel et al. (2007) como o principal limite para o desenvolvimento da cultura da macadâmia no Brasil.

Algumas observações, efetuadas no decorrer do experimento, podem ajudar na tentativa de se explicar a diferença entre as produções citadas em outros trabalhos (Pimentel et al., 2007) e as obtidas na presente pesquisa (Tabelas 2 e 3 ). Trincheiras abertas no terceiro ano de cultivo evidenciaram que as raízes das plantas de macadâmia estendiam-se além da projeção das copas, por debaixo das copas dos cafeeiros vizinhos, e aproveitavam as melhores condições para o desenvolvimento de raízes proporcionadas pelo microclima modificado pelo sombreamento dos cafeeiros ao solo. Além disso, as plantas de macadâmia aproveitavam as condições de fertilidade, proporcionadas pelas adubações aplicadas aos cafeeiros, para desenvolverem raízes e explorar maiores volumes de solo. Há também a possibilidade de a adubação atualmente preconizada para macadâmia no Brasil ser insuficiente para seu pleno desenvolvimento. Fletcher et al. (2010) relataram que produtores australianos utilizam doses próximas de $150 \mathrm{~kg} \mathrm{ha}^{-1}$ $\mathrm{N}$ por ano, três vezes acima das recomendações brasileiras de $50 \mathrm{~kg} \mathrm{ha}^{-1}$ de $\mathrm{N}$ por ano, para produções de até $5.000 \mathrm{~kg} \mathrm{ha}^{-1}$ de nozes (Barbosa et al., 1996). Além disso, é provável que o uso de irrigação seja responsável por parte do bom desempenho observado no presente experimento. Assim, mais pesquisas são necessárias para elucidar as diferenças de produções obtidas para os referidos sistemas, para viabilizar economicamente a cultura da noz-macadâmia.

Para o caso de um consórcio permanente ou arborização de cafezais, é desejável que a planta a ser consorciada colabore na renda do sistema e produza um nível de sombreamento que ofereça proteção eficaz contra condições ambientais nocivas ao cafeeiro, porém, adequado à produtividade deste. As cultivares nacionais de macadâmia apresentaram maior produtividade, entretanto, seu vigoroso crescimento horizontal impossibilitou a mecanização do sistema; assim, outros estudos devem ser feitos, com a utilização de podas e avaliação da produção 
nesta condição. Entre estas cultivares, destacou-se a IAC 4-20, com menor porte. As cultivares havaianas apesar de menos produtivas, apresentaram crescimento lateral menor, o que facilita a mecanização do consórcio e, provavelmente, proporciona menor competição por espaço com os cafeeiros.

\section{Conclusões}

1. Em cultivo consorciado com café arábica irrigado, as cultivares nacionais de macadâmia são mais produtivas, com destaque para a IAC 4 -12B.

2. As cultivares nacionais de macadâmia (IAC 9-20, IAC 4-12B e IAC 4-20) apresentam menor altura, porém, com copas de diâmetro maior.

\section{Referências}

BARBOSA, W.; OJIMA, M.; CAMPO-DALL'ORTO, F.A.; RAIJ, B. van. Frutas de clima temperado - III. Caqui, maçã, macadâmia, pecã e pêra. In: RAIJ, B. van; CANTARELLA, H.; QUAGGIO, J.A.; FURLANI, A.M.C. (Ed.). Recomendações de adubação e calagem para o Estado de São Paulo. 2.ed. Campinas: Instituto Agronômico, 1996. p.141. (IAC. Boletim técnico, 100).

CAMARGO, M.B.P. de. The impact of climatic variability and climate change on arabic coffee crop in Brazil. Bragantia, v.69, p.239-247, 2010.

CENTRO DE PESQUISAS METEOROLÓGICAS E CLIMÁTICAS APLICADAS À AGRICULTURA. Clima dos municípios paulistas: a classificação climática de Koeppen para o Estado de São Paulo. Disponível em: < http://www.cpa.unicamp.br/ outras-informacoes/clima-dos-municipios-paulistas.html>. Acesso em: 14 nov. 2012.

DAMATTA, F.M. Ecophysiological constraints on the production of shaded and unshaded coffee: a review. Field Crops Research, v.86, p.99-114, 2004.

FLETCHER, A.; RENNENBERG, H.; SCHMIDT, S. Nitrogen partitioning in orchard-grown Macadamia integrifolia. Tree Physiology, v.30, p.244-256, 2010.

JARAMILLO-BOTERO, C.; SANTOS, R.H.S.; MARTINEZ, H.E.P.; CECON, P.R.; FARDIN, M.P. Production and vegetative growth of coffee trees under fertilization and shade levels. Scientia Agricola, v.67, p.639-645, 2010.

MARROCOS, P.C.L.; MARTINEZ, H.E.P.; VENEGAS A.V.H.; BRUCKNER, C.H.; CANTARUTTI, R.B. Interação P x Fe em mudas de macadâmia. Revista Brasileira de Fruticultura, v.25, p.323-325, 2003.

MARTIN, B.N. Viabilidade econômica da produção da noz macadâmia no Estado de São Paulo. Informações Econômicas, v.22, p.9-53, 1992.

MCFADYEN, L.M.; ROBERTSON, D.; SEDGLEY, M.; KRISTIANSEN, P.; OLESEN, T. Effects of the ethylene inhibitor aminoethoxyvinylglycine (AVG) on fruit abscission and yield on pruned and unpruned macadamia trees. Scientia Horticulturae, v.137, p.125-130, 2012.

MCFADYEN, L.M.; ROBERTSON, D.; SEDGLEY, M.; KRISTIANSEN, P.; OLESEN, T. Post-pruning shoot growth increases fruit abscission and reduces stem carbohydrates and yield in macadamia. Annals of Botany, v.107, p.993-1001, 2011.

NICOLELI, M.; MOLLER, H.D. Análise da competitividade dos custos do café orgânico sombreado irrigado. Custos e Agronegócio, v.2, p.29-44, 2006.

PENONI, E. dos S.; PIO, R.; RODRIGUES, F.A.; MARO, L.A.C.; COSTA, F.C. Análise de frutos e nozes de cultivares de nogueira-macadâmia. Ciência Rural, v.41, p.2080-2083, 2011.

PEZZOPANE, J.R.M.; MARSETTI, M.M.S.; FERRARI, W.R.; PEZZOPANE, J.E.M. Alterações microclimáticas em cultivo de café conilon arborizado com coqueiro-anão-verde. Revista Ciência Agronômica, v.42, p.865-871, 2011.

PEZZOPANE, J.R.M.; MARSETTI, M.M.S.; SOUZA, J.M. de; PEZZOPANE, J.E.M. Condições microclimáticas em cultivo de café conilon a pleno sol e arborizado com nogueira macadâmia. Ciência Rural, v.40, p.1257-1263, 2010.

PEZZOPANE, J.R.M.; PEDRO JÚNIOR, M.J.; GALLO, P.B. Radiação solar e saldo de radiação em cultivo de café a pleno sol e consorciado com banana 'Prata Anã'. Bragantia, v.64, p.485-497, 2005.

PEZZOPANE, J.R.M.; PEDRO JÚNIOR, M.J.; GALLO, P.B.; FAZUOLI, L.C. Caracterização microclimática em cultivo consorciado café/banana. Revista Brasileira de Engenharia Agrícola e Ambiental, v.11, p.256-264, 2007.

PIMENTEL, L.D.; SANTOS, C.E.M. dos; WAGNER JÚNIOR, A.; SILVA, V.A.; BRUCKNER, C.H. Estudo de viabilidade econômica na cultura da noz-macadâmia no Brasil. Revista Brasileira de Fruticultura, v.29, p.500-507, 2007.

RAIJ, B. van; CANTARELLA, H.; QUAGGIO, A.J. Estimulantes - café. In: RAIJ, B. van; CANTARELLA, H.; QUAGGIO, J.A.; FURLANI, A.M.C. (Ed.). Recomendações de adubação e calagem para o Estado de São Paulo. 2.ed. Campinas: Instituto Agronômico e Fundação IAC, 1996. p.97-101. (IAC. Boletim técnico, 100).

RICCI, M. dos S.F.; COSTA, J.R.; PINTO, A.N.; SANTOS, V.L. da S. Cultivo orgânico de cultivares de café a pleno sol e sombreado. Pesquisa Agropecuária Brasileira, v.41, p.569-575, 2006.

SACRAMENTO, C.K.; PEREIRA F.M. Fenologia da floração da nogueira macadâmia (Macadamia integrifolia Maiden \& Betche) nas condições climáticas de Jaboticabal, São Paulo, Brasil. Revista Brasileira de Fruticultura, v.25, p.19-22, 2003.

SANTOS, H.G. dos; JACOMINE, P.K.T.; ANJOS, L.H.C. dos; OLIVEIRA, V.A. de; OLIVEIRA, J.B. de; COELHO, M.R.; LUMBRERAS, J.F.; CUNHA, T.J.F. (Ed.). Sistema brasileiro de classificação de solos. 2.ed. Rio de Janeiro: Embrapa Solos, 2006. $306 \mathrm{p}$.

SCHNEIDER, L.M; ROLIM, G.de S.; SOBIERAJSKI, G. da R.; PRELA-PANTANO, A.; PERDONÁ, M.J. Zoneamento 
agroclimático de nogueira-macadâmia para o Brasil. Revista Brasileira de Fruticultura, v.34, p.515-524, 2012.

SOBIERAJSKI, G. da R.; BARBOSA, W.; BETTIOL NETO, J.E.; CHAGAS, E.A.; CAMPO-DALL'ORTO, F.A. Caracterização dos estágios fenológicos em sete cultivares e seleções de nogueira-macadâmia. Revista Brasileira de Fruticultura, v.29, p.690-694, 2007.
SOBIERAJSKI, G. da R.; FRANCISCO, V.L.F. dos S.; ROCHA, P.; GHILARDI, A.A.; MAIA, M.L. Noz-macadâmia: produção, mercado e situação no Estado de São Paulo. Informações Econômicas, v.36, p.25-36, 2006.

VIEIRA, T.G.C.; ALVES, H.M.R.; BERTOLDO, M.A.; SOUZA, V.C.O. de. Geothecnologies in the assessment of land use changes in coffee regions of the state of Minas Gerais in Brasil. Coffee Science, v.2, p.142-149, 2007.

Recebido em 22 de maio de 2012 e aprovado em 7 de outubro de 2012 